\title{
Evaluation of miniscrew angulation in the posterior maxilla using cone-beam computed tomographic image
}

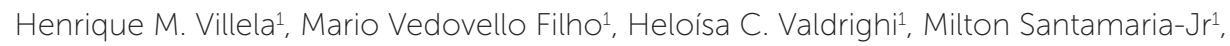

Carolina Carmo de Menezes', Silvia A. S. Vedovello

DOI: https://doi.org/10.1590/2177-6709.23.1.046-053.oar

Objective: This study aimed at evaluating whether changes in the insertion angle is a determining factor in the positioning of the miniscrews body in a region with larger interradicular space in the posterior maxilla. Methods: Analysis of 60 posterior maxillary quadrants were made using images obtained by means of cone-beam computed tomographic image (CBCT), with $0.076-\mathrm{mm}$ voxel, which presented a real miniscrew inserted in the mesial region of the maxillary first molars, serving as reference point for the placement of the virtual miniscrews. Measurements of the distances between roots were made in three points on the body of the virtual miniscrews (A, B and C), at four different angulations, $70^{\circ}, 60^{\circ}, 50^{\circ}$ and $40^{\circ}\left(\mathrm{T}_{1}\right.$ to $\left.\mathrm{T}_{4}\right)$, in relation to the long axis of the second premolar. This evaluation was made in four groups, selected in accordance with the disposition of the roots of the second premolars and first molars: Group 1 (all types of roots), Group 2 (convergent roots), Group 3 (divergent roots) and Group 4 (parallel roots). Results: There were no statistically significant differences in the measurements of points A, B and C, at the different angles $\left(70^{\circ}, 60^{\circ}, 50^{\circ}\right.$ and $\left.40^{\circ}\right)$ and in the different groups $(p>0.05)$. Conclusions: Changes in the insertion angle is not a determinant factor in the positioning of miniscrews body in regions with larger interradicular space in posterior maxilla.

Keywords: Bone screw. Implants. Tomography. Orthodontics.

Objetivo: o presente estudo objetivou avaliar se alterações no ângulo de inserção do miniparafuso são um fator decisivo para a adaptação do corpo do parafuso em áreas com espaço inter-radicular aumentado, na região posterior da maxila. Métodos: foram realizadas análises em 60 quadrantes maxilares posteriores, a partir de imagens obtidas por tomografia computadorizada de feixe cônico (TCFC), com voxel de $0,076 \mathrm{~mm}$, as quais apresentavam um miniparafuso real inserido na região mesial dos primeiros molares superiores, utilizado como ponto de referência para a inserção de miniparafusos virtuais. As distâncias inter-radiculares foram mensuradas utilizando-se três pontos marcados no corpo dos miniparafusos virtuais $\left(A, B\right.$ e C), inseridos com quatro angulações diferentes $\left(70^{\circ}, 60^{\circ}, 50^{\circ}\right.$ e $\left.40^{\circ}\right)\left(\mathrm{T}_{1}\right.$ a $\left.\mathrm{T}_{4}\right)$ em relação ao longo eixo do segundo pré-molar. A avaliação foi realizada em quatro grupos, selecionados de acordo com a disposição das raízes dos segundos pré-molares e primeiros molares: Grupo 1 - contendo todos os tipos de raízes; Grupo 2 - raízes convergentes; Grupo 3 - raízes divergentes; e Grupo 4 - raízes paralelas. Resultados: não houve diferença estatisticamente significativa entre as medidas dos pontos A, B e C nas diferentes angulações $\left(70^{\circ}, 60^{\circ}, 50^{\circ}\right.$ e $\left.40^{\circ}\right)$ ou entre os grupos $(p>0,05)$. Conclusões: alterações no ângulo de inserção dos miniparafusos não são um fator decisivo para a adaptação do corpo do parafuso, em áreas com espaço inter-radicular aumentado entre primeiro molar e segundo pré-molar superiores.

Palavras-chave: Parafuso. Miniparafuso. Tomografia. Ortodontia.

${ }^{1}$ Uniararas, Fundação Hermínio Ometto, Programa de Pós-graduação em Ortodontia (Araras/SP, Brazil).

» The authors report no commercial, proprietary or financial interest in the products or companies described in this article.

Submitted: March 23, 2017 - Revised and accepted: October 01, 2017
How to cite Villela HM, Vedovello Filho M, Valdrighi HC, Santamaria-Jr M, Menezes CC, Vedovello SAS. Evaluation of miniscrew angulation in the posterior maxilla using cone-beam computed tomographic image. Dental Press J Orthod. 2018 Jan-Feb;23(1):46-53.

DOI: https://doi.org/10.1590/2177-6709.23.1.046-053.oar

Contact address: Silvia A. S. Vedovello

Av. Dr. Maximiliano Baruto, 500, Jardim Universitário - Araras/SP

CEP: 13.607-339 - E-mail: silviavedovello@gmail.com 


\section{INTRODUCTION}

Miniscrews have brought a new perspective to orthodontic treatment due to their low cost, effectiveness and easy clinical management. ${ }^{1,2,3}$ Although the procedure for miniscrew insertion is simple, some care must be taken with the purpose of minimizing the risks of the miniscrew body contacting the roots of teeth, such as: evaluating the bone availability in the interradicular space; use of simplified surgical guides, and the use of a safe surgical protocol. ${ }^{1}$ The possibilities of causing damage to periodontal structure and the roots must not be underestimated. Among the problems can be included: displacement of bone into the periodontal ligament space; damage to cement; damage to dentin and pulp damage. . $^{4-7}$

One of the factors that may vary during miniscrew insertion into the maxilla is angulation, which may be more perpendicular or more angulated in relation to the vestibular bone cortical surface, or in relation to the long axis of the teeth. Some authors have recommended a more perpendicular insertion into the maxilla, since this factor would diminish the risk of the screw body contacting the roots, and generates a line of action of force closer to the center of resistance. ${ }^{8}$ Other authors have recommended miniscrew insertion into the maxilla with an angulation of $30^{\circ}$ to $40^{\circ}$ in relation to the long axis of the tooth, with the purpose of minimizing the risks of the screw contacting the roots. ${ }^{9-11}$

Primary stability may be increased when the miniscrew is inserted at angles of $60^{\circ}$ to $70^{\circ}$ in relation to the bone surface, in regions with thicker cortical bone, but for this purpose a higher torque is demanded for its insertion. However, this increased angulation may cause a higher failure rate due to excessive pressure on the bone. ${ }^{12}$ The bone density in the posterior region of the maxilla is lower than it is in the mandible, and this area also presents a thin vestibular cortical. ${ }^{13-15}$ Studies in the mandibles of human cadavers and using finite elements method have shown that the insertion of screws at $90^{\circ}$ in relation to the bone surface offered greater resistance and less stress on cortical bone than that of screws inserted at $60^{\circ}$ and $30^{\circ} .{ }^{16}$ Stability and resistance to failure do not depend on the orientation of miniscrew implantation in relation to the bone surface, however, miniscrews inserted at $90^{\circ}$ presented greater stability in shear tests, in comparison with those inserted at $45^{\circ}$. This higher degree of stability occurred due to the line of action of force being positioned closer to the long axis of screws perpendicular to the bone surface. ${ }^{17}$ Screw insertion in a more apical and angled position not only increases the risk of contact with the maxillary sinus, but also increases the risk of sliding during its insertion. ${ }^{18}$ The miniscrew may be placed at an angle between $55^{\circ}$ and $70^{\circ}$ in relation to the occlusal plane, in the infrazygomatic crest region, above the maxillary first molar, with the purpose of preventing its contact with the root. However, in order for this strategy to be efficient, the miniscrew must be inserted at a distance of 14 to $16 \mathrm{~mm}$ from the occlusal plane. ${ }^{19}$ One of the greater risk factors of this anchorage system is inflammation of the peri-screw soft tissues, which occurs when screws are inserted into the alveolar mucosa. To prevent this from occurring, the screws must preferably be inserted into keratinized mucosa..$^{20,21}$

During planning of screw insertion into the molar region, the location of the maxillary sinus must be observed and it perforation prevented, since it could lead to complications such as sinusitis and mucosal retention cysts. ${ }^{18,22}$ In-depth knowledge of anatomic relations between the roots and adjacent structures, with the use of tomography, is essential to prevent root injuries; and studies to evaluate which would be the best position of the miniscrew to diminish the possibility of contact with the roots, are of fundamental importance. This is because the proximity of the miniscrew to the root is a risk factor that may lead to the loss of stability and consequent failure of this device as an orthodontic anchorage. ${ }^{23,24}$ Studies conducted in human maxillae and mandibles, and studies in tomographies have concluded that the region between the maxillary first molar and second premolar, from the vestibular direction, represent the safest region for performing the insertion of miniscrews at the height of 6 to $8 \mathrm{~mm}$ from the cervical line. ${ }^{9,24}$

The objective of this study was to evaluate if the change in insertion angle is a determining factor in the positioning of the miniscrews body in a region with larger interradicular space in the posterior maxilla, using real miniscrews inserted in this region with clinical success, as guidance. 


\section{MATERIAL AND METHODS}

This study received approval from a Ethics Committee (FHO/Uniararas, protocol \# 2.081.877). The convenience sample comprised images selected from a file containing orthodontics records. These had been captured by means of cone-beam computed tomographic image (CBCT) with $0.076-\mathrm{mm}$ voxel, in a Kodak 9000 3D tomograph (Kodak Dental Systems, Carestream Health, Rochester, NY, USA), which belonged to the file of one of the researchers, according to the following inclusion criteria:

" Brazilian patients of both genders.

"Who had undergone corrective orthodontic treatment.

»With real miniscrews inserted between the maxillary first molars and second premolars at an advanced stage of leveling.

»With real miniscrews inserted by the same clinician professional.

" With CBCT taken by the same tomograph.

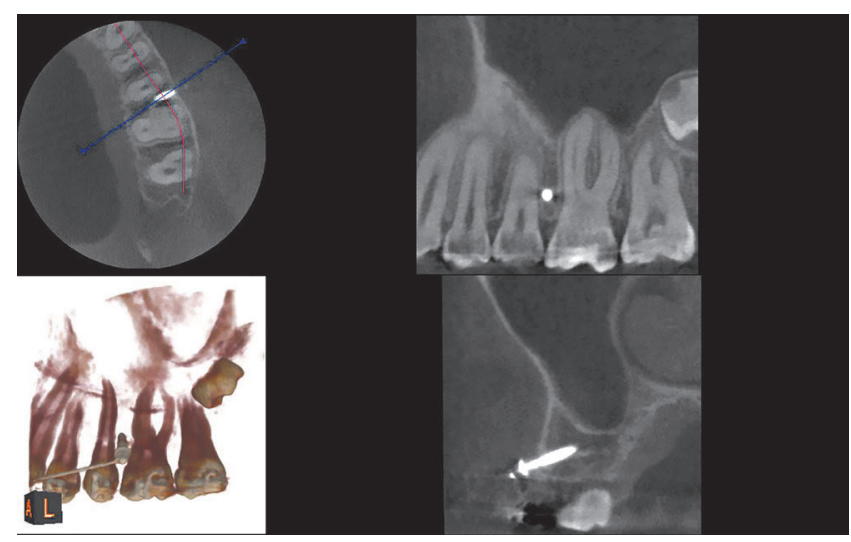

Figure 1 - $C B C T$ visualization of three slices and 3D reconstruction.
The CBCT images of patients who did not fall within the selection criteria were excluded. The final sample consisted of 60 maxillary posterior quadrants of 35 patients, with 26 being female and 09 male, and 30 quadrants from the right and 30 from the left side.

The CBCT depicted miniscrews previously inserted in the mesial region of the maxillary first molars, which served as reference for positioning the virtual miniscrews (Fig 1). The virtual miniscrews were created, coinciding with the real miniscrews in the vestibular cortical region. This site represents the point of introduction of the miniscrew into the cortical bone and was chosen according to the orthodontic planning. Usually, this site is found in the region of keratinized mucosa, which determines the limit in height for the insertion of a miniscrew. This height may range between 6 to $8 \mathrm{~mm}$ apical to the line of the orthodontic arch. The virtual miniscrews were created with four different angulations: $70^{\circ}, 60^{\circ}, 50^{\circ}$ and $40^{\circ}$, in relation to the long axis of the second premolar (Fig 2).

The insertion and changes in angulation of the virtual miniscrews were performed by means of a specific software program (CS 3D imaging software, Kodak Dental Systems, Carestream Health, Rochester, NY, USA), which is a visualizer of CBCT images in DICOM (Digital Imaging and Communications in Medicine) format. The distance between the roots of the first molars and second premolars was evaluated in three specific points on the body of the virtual miniscrews, on a slice constructed parallel to the long axis of each virtual inclination. These three points were determined by measuring $2 \mathrm{~mm}$, $4 \mathrm{~mm}$ and $6 \mathrm{~mm}$ from the point of the virtual miniscrews, which presented a body length of $8 \mathrm{~mm}$. The measurements were determined on a slice constructed parallel to the long axis of each virtual inclination. The points were denominated as follows: A) $2 \mathrm{~mm}$, B) $4 \mathrm{~mm}$ and C) $6 \mathrm{~mm}$ from the tip of the miniscrew, respectively. These three

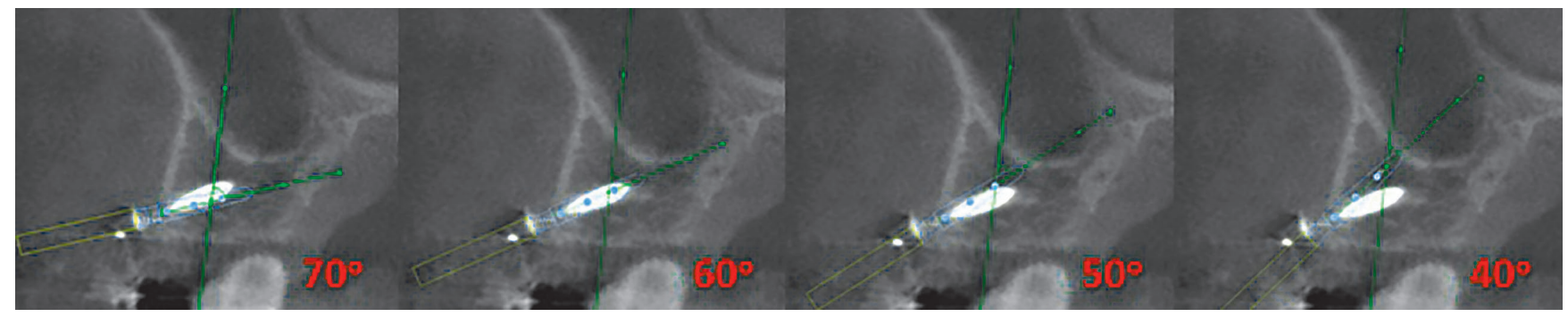

Figure 2 - Virtual miniscrews at $70^{\circ}, 60^{\circ}, 50^{\circ}$ and $40^{\circ}$ of inclination in relation to the long axis of the second premolar, in the transaxial slice 
distances were measured at the four angulations of the miniscrew, determining: $\mathrm{T} 1=70^{\circ}, \mathrm{T} 2=60^{\circ}, \mathrm{T} 3=50^{\circ}$ and $\mathrm{T} 4=40^{\circ}$ (Fig 3). Then, they were duly recorded in accordance with their location (A, B and C) and the angle $\left(70^{\circ}, 60^{\circ}, 50^{\circ}\right.$ and $\left.40^{\circ}\right)$ (Table 1$)$.

During CBCT evaluation the different shapes and dispositions of the roots were observed, which resulted in distinct interradicular spaces. From this observation, three groups were created, which presented interradicular spaces with different characteristics, based on the disposition of the maxillary first molar roots in relation to those of the second premolars. The groups were denominated as follows, regarding roots: convergent, divergent and parallel. The convergent roots, composed of $5(8.33 \%)$ tomographies, presented a reduction in interradicular space in the direction towards the apices, due to convergence of the first molar roots in the direction of the premolar roots (Fig 4). The divergent roots, composed of $21(35 \%)$ tomographies, presented a constant and significant increase in interradicular space in the direction towards the apices (Fig 5). The parallel roots, composed of 34 (56.66\%) tomographies, presented an interradicular space that remained equal in the direction towards the apex, however, with a increase in this space only in the apical third (Fig 6).

Evaluations of the spaces between the roots at the four angulations were made in the four different groups: Group 1, with all the tomographies without distinction of the types of roots; Group 2, with convergent roots; Group 3, with divergent roots; Group 4, with parallel roots.

The CBCT were numbered in alphabetical order according to the patient's first name. When there were two tomographies for a patient, one of each side, then

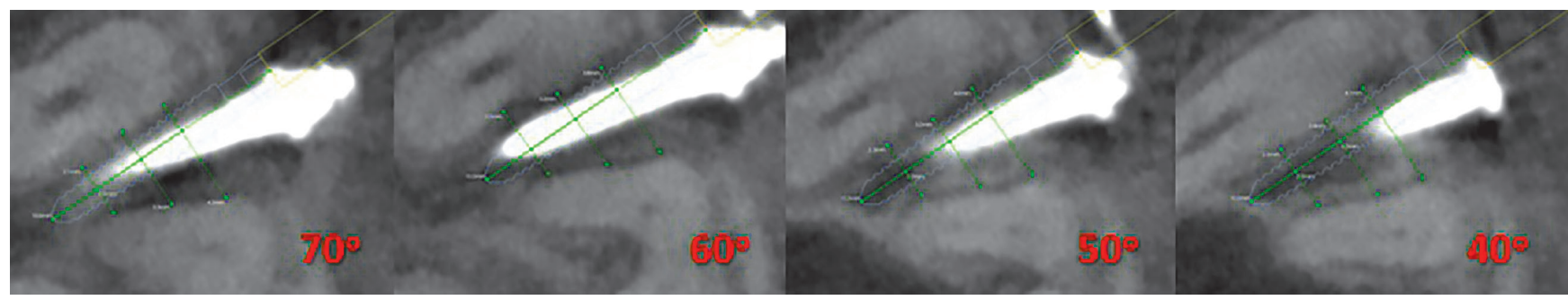

Figure 3 - Measurement of the distances between the root of the molar and premolar at points (A), (B) and (C), located at $2.0 \mathrm{~mm}, 4.0 \mathrm{~mm}$ and $6.0 \mathrm{~mm}$, respectively, from the tip of the miniscrew at $70^{\circ}\left(T_{1}\right), 60^{\circ}\left(T_{2}\right), 50^{\circ}\left(T_{3}\right)$ and $40^{\circ}\left(T_{4}\right)$ of inclination in relation to the long axis of the second premolar, in the transaxial slice.

Table 1 - Values of measurements (A), (B) and (C) by angle in study population in all types of roots $(n=60)$.

\begin{tabular}{|c|c|c|c|c|c|c|}
\hline Points & Angles & Mean & $\begin{array}{l}\text { Standard } \\
\text { Deviation }\end{array}$ & Minimum Value & Maximum Value & P-value** \\
\hline \multirow{4}{*}{ A } & $\mathrm{T}_{1}\left(70^{\circ}\right)$ & 3.98 & 0.92 & 2.20 & 6.30 & \multirow{4}{*}{0.25} \\
\hline & $T_{2}\left(60^{\circ}\right)$ & 4.08 & 0.99 & 2.30 & 6.60 & \\
\hline & $\mathrm{T}_{3}\left(50^{\circ}\right)$ & 4.22 & 1.10 & 2.10 & 6.60 & \\
\hline & $\mathrm{T}_{4}\left(40^{\circ}\right)$ & 4.36 & 1.29 & 2.20 & 8.90 & \\
\hline \multirow{4}{*}{$\mathrm{B}$} & $\mathrm{T}_{1}\left(70^{\circ}\right)$ & 3.86 & 0.79 & 2.30 & 5.40 & \multirow{4}{*}{0.47} \\
\hline & $T_{2}\left(60^{\circ}\right)$ & 3.88 & 0.84 & 2.20 & 5.50 & \\
\hline & $\mathrm{T}_{3}\left(50^{\circ}\right)$ & 3.94 & 0.89 & 1.80 & 5.90 & \\
\hline & $T_{4}\left(40^{\circ}\right)$ & 4.09 & 1.00 & 1.70 & 6.30 & \\
\hline \multirow{4}{*}{ C } & $\mathrm{T}_{1}\left(70^{\circ}\right)$ & 4.35 & 0.90 & 2.40 & 6.40 & \multirow{4}{*}{0.39} \\
\hline & $T_{2}\left(60^{\circ}\right)$ & 4.38 & 0.91 & 2.40 & 6.70 & \\
\hline & $\mathrm{T}_{3}\left(50^{\circ}\right)$ & 4.45 & 0.97 & 2.40 & 6.90 & \\
\hline & $\mathrm{T}_{4}\left(40^{\circ}\right)$ & 4.63 & 1.15 & 2.50 & 7.70 & \\
\hline
\end{tabular}

(A) $2 \mathrm{~mm}$, (B) $4 \mathrm{~mm}$ and (C) $6 \mathrm{~mm}$ from the tip of the miniscrew. ${ }^{* *}$ ANOVA, $p<0.05$. 


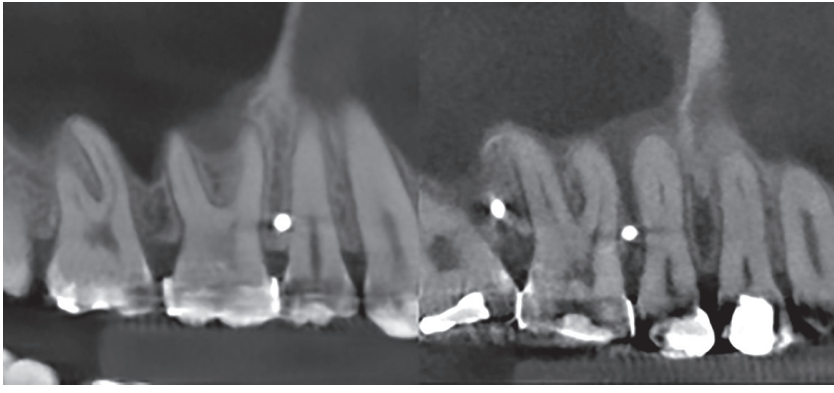

Figure 4 - Convergent roots

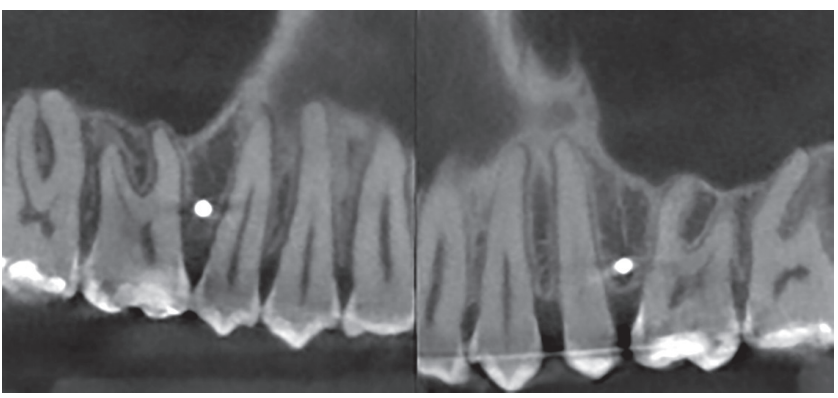

Figure 5 - Divergent roots.

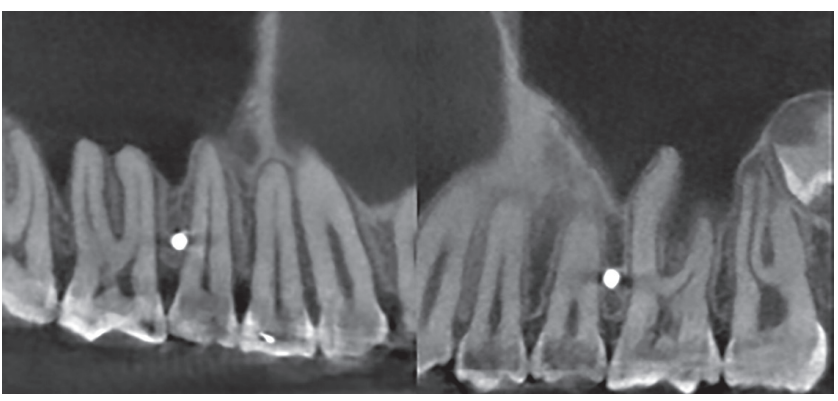

Figure 6 - Parallel roots.

the first to be numbered was the right side, and then the left side. Thus, all the tomographies had a number. For the intra-examiner test of agreement, the following tomography numbers were used: 10, 20, 30, 40, 50 and 60. All measurements were taken twice by the same operator blinded to group status, with an interval of ten days. ${ }^{25}$ For the agreement test, the Kappa statistics were calculated and obtained 0.91, which indicates excellent agreement between exams. The value varied from 0.89 for the measurement $\mathrm{B}, 0.91$ for the measurement $\mathrm{C}$ and 0.94 for the measurement $\mathrm{A}$.

\section{Statistical analysis}

The variables were descriptively analyzed, and their measurements of central tendency and dispersion were calculated. The Kolmogorov-Smirnov test was used to analyze normality of distribution. After proof of normality of the data, the Student's-t test was used to identify differences among the groups. In the presence of three or more groups of comparisons, the option was to use the Analysis of Variance (ANOVA), followed by the Tukey test. All the analyses were performed using a level of significance of $95 \%$.

\section{RESULTS}

\section{Evaluation of Group 1}

All the types of roots $(n=60)$

The highest obtained values for the distances between roots were for measurement $\mathrm{C}$, followed by $\mathrm{A}$ and then $\mathrm{B}$, considering all types of roots and the subdivision by angles (Table 1). This first evaluation only registered the fact that in the middle portion of the miniscrew, which is found at approximately $4 \mathrm{~mm}$ from the cortical (bone), there is the region with the smallest space between the roots. In the evaluation of Group 1 (all the roots) at different angles, there was a clear trend towards increase in the values from $T_{1}$ to $T_{4}$, although this increase was not statistically significant (Table 2).

\section{Evaluation of Group 2 - convergent roots $(n=5)$}

In the evaluation of Group 2 (convergent roots) at different angles, there was a trend towards reduction in the values from $T_{1}$ to $T_{4}$, although this reduction was not statistically significant. The cases of convergent roots, composed of 5 tomographies, $8.33 \%$ of the sample of 60 tomographies, on an average, presented a discrete trend towards reduction in interradicular space, when the angle was diminished; however, it was not statistically significant (Table 2).

\section{Evaluation of Group 3 - divergent roots $(n=21)$}

In the evaluation of Group 3 (divergent roots) at different angles, there was a trend towards increase in the values from $T_{1}$ to $T_{4}$, although this increase was not statistically significant. The cases of divergent roots, composed of 21 tomographies, 35\% of the sample of 60 tomographies, on an average, presented a trend towards increase in interradicular space, particularly at Point A, when the angle was diminished. However, it was not statistically significant (Table 2). 
Table 2 - Values of measurements (A), (B) and (C) by angle in a samples with convergent roots ( $n=05)$, divergent roots $(n=21)$ and parallel roots ( $n=34)$.

\begin{tabular}{|c|c|c|c|c|c|}
\hline Roots & Points & Angles & Mean & Standard Deviation & P-value** \\
\hline \multirow{12}{*}{ Convergent } & \multirow{4}{*}{ A } & $T_{1}\left(70^{\circ}\right)$ & 2.98 & 0.67 & \multirow{4}{*}{0.99} \\
\hline & & $T_{2}\left(60^{\circ}\right)$ & 2.92 & 0.69 & \\
\hline & & $\mathrm{T}_{3}\left(50^{\circ}\right)$ & 2.88 & 0.62 & \\
\hline & & $\mathrm{T}_{4}\left(40^{\circ}\right)$ & 2.92 & 0.30 & \\
\hline & \multirow{4}{*}{$\mathrm{B}$} & $T_{1}\left(70^{\circ}\right)$ & 3.06 & 0.32 & \multirow{4}{*}{0.70} \\
\hline & & $T_{2}\left(60^{\circ}\right)$ & 2.98 & 0.28 & \\
\hline & & $\mathrm{T}_{3}\left(50^{\circ}\right)$ & 2.76 & 0.58 & \\
\hline & & $\mathrm{T}_{4}\left(40^{\circ}\right)$ & 2.78 & 0.62 & \\
\hline & \multirow{4}{*}{ C } & $T_{1}\left(70^{\circ}\right)$ & 3.80 & 0.72 & \multirow{4}{*}{0.99} \\
\hline & & $T_{2}\left(60^{\circ}\right)$ & 3.72 & 0.66 & \\
\hline & & $\mathrm{T}_{3}\left(50^{\circ}\right)$ & 3.72 & 0.71 & \\
\hline & & $T_{4}\left(40^{\circ}\right)$ & 3.78 & 0.77 & \\
\hline \multirow{12}{*}{ Divergent } & \multirow{4}{*}{ A } & $T_{1}\left(70^{\circ}\right)$ & 4.59 & 0.89 & \multirow{4}{*}{0.07} \\
\hline & & $T_{2}\left(60^{\circ}\right)$ & 4.80 & 0.93 & \\
\hline & & $T_{3}\left(50^{\circ}\right)$ & 5.05 & 0.97 & \\
\hline & & $\mathrm{T}_{4}\left(40^{\circ}\right)$ & 5.40 & 1.29 & \\
\hline & \multirow{4}{*}{$\mathrm{B}$} & $T_{1}\left(70^{\circ}\right)$ & 4.45 & 0.66 & \multirow{4}{*}{0.31} \\
\hline & & $T_{2}\left(60^{\circ}\right)$ & 4.52 & 0.70 & \\
\hline & & $\mathrm{T}_{3}\left(50^{\circ}\right)$ & 4.63 & 0.72 & \\
\hline & & $\mathrm{T}_{4}\left(40^{\circ}\right)$ & 4.86 & 0.87 & \\
\hline & \multirow{4}{*}{ C } & $T_{1}\left(70^{\circ}\right)$ & 4.84 & 0.87 & \multirow{4}{*}{0.50} \\
\hline & & $\mathrm{T}_{2}\left(60^{\circ}\right)$ & 4.85 & 0.90 & \\
\hline & & $\mathrm{T}_{3}\left(50^{\circ}\right)$ & 4.98 & 0.94 & \\
\hline & & $\mathrm{T}_{4}\left(40^{\circ}\right)$ & 5.25 & 1.20 & \\
\hline \multirow{12}{*}{ Parallel } & \multirow{4}{*}{ A } & $T_{1}\left(70^{\circ}\right)$ & 3.75 & 0.74 & \multirow{4}{*}{0.79} \\
\hline & & $T_{2}\left(60^{\circ}\right)$ & 3.81 & 0.74 & \\
\hline & & $\mathrm{T}_{3}\left(50^{\circ}\right)$ & 3.91 & 0.86 & \\
\hline & & $\mathrm{T}_{4}\left(40^{\circ}\right)$ & 3.92 & 0.86 & \\
\hline & \multirow{4}{*}{ B } & $T_{1}\left(70^{\circ}\right)$ & 3.62 & 0.67 & \multirow{4}{*}{0.63} \\
\hline & & $T_{2}\left(60^{\circ}\right)$ & 3.62 & 0.70 & \\
\hline & & $\mathrm{T}_{3}\left(50^{\circ}\right)$ & 3.68 & 0.69 & \\
\hline & & $\mathrm{T}_{4}\left(40^{\circ}\right)$ & 3.81 & 0.76 & \\
\hline & \multirow{4}{*}{ C } & $\mathrm{T}_{1}\left(70^{\circ}\right)$ & 4.13 & 0.83 & \multirow{4}{*}{0.68} \\
\hline & & $T_{2}\left(60^{\circ}\right)$ & 4.19 & 0.83 & \\
\hline & & $T_{3}\left(50^{\circ}\right)$ & 4.24 & 0.89 & \\
\hline & & $T_{4}\left(40^{\circ}\right)$ & 4.39 & 1.02 & \\
\hline
\end{tabular}

(A) $2 \mathrm{~mm}$, (B) $4 \mathrm{~mm}$ and (C) $6 \mathrm{~mm}$ from the tip of the miniscrew. ${ }^{* *}$ ANOVA, $p<0.05$.

\section{Evaluation of Group 4 - parallel roots $(n=34)$}

In the evaluation of Group 4 (parallel roots) at different angles, there was a slight trend towards increase in the values from $\mathrm{T}_{1}$ to $\mathrm{T}_{4}$, although this increase was not statistically significant. The cases of parallel roots, composed of 34 tomographies, 56.66\% of the sample of 60 tomographies, on an average, presented a slight trend towards increase in interradicular space when the angle was diminished. However, it was not statistically significant (Table 2). 
The results of the evaluation of the four groups were very similar. There were cases in which an increase in space occurred when the insertion angle was reduced. However, there were also simulations in which the space did not change, and in other cases a reduction in space occurred. However, on an average, this trend towards increase or reduction was not statistically significantly. The interradicular spaces along the miniscrew did not increase similarly in all cases in which the angulation was changed from $70^{\circ}$ to $40^{\circ}$. The distances between the roots varied differently according to the region of the miniscrew body.

\section{DISCUSSION}

This study evaluated miniscrews angulation in the space between the first molars and second premolars because, according to several authors, this is a region where there is greater availability of space in the maxilla from the vestibular side, which present signifcant clinical application. ${ }^{9,24}$

The choice of angulation is not unanimous. Some authors have recommended miniscrew insertion into the maxilla with an angulation of $30^{\circ}$ to $40^{\circ}$ in relation to the long axis of the tooth, with the purpose of minimizing the risks of contact of the screw with the roots. ${ }^{9-11}$ However, other authors have recommended more perpendicular miniscrew insertion into the maxilla, because of the understanding that this factor does not increases the risk of screw contact with the root, and also provides better distribution of force on the cortical bone..$^{8,16,17}$

The present study recorded the fact that in the middle portion of the miniscrew, which is found at approximately $4 \mathrm{~mm}$ from the cortical (bone), there is the region with the least space between the roots. Thus, when introducing the miniscrew into the maxilla from the vestibular side, the moment of greatest risk was when the body of the miniscrew was passing through this region, which is equivalent to half of its length when using a screw with a body length of $8 \mathrm{~mm}$. One must pay attention to the patient's sensitivity or to an increase in resistance to the insertion when 4 to $5 \mathrm{~mm}$ of the miniscrew body are intraosseously inserted.
When miniscrews were inserted at an angle of $50^{\circ}$ and $40^{\circ}$, there was superimposition of the virtual screw body on the maxillary sinus in 24 tomographies, equivalent to $40 \%$ of the total number of evaluations. This fact must be avoided, because it may lead to complications such as sinusitis and mucosal retention cysts. ${ }^{18,22}$ Moreover, screw insertion in a more apical and angled position not only increases the risk of contact with the maxillary sinus, but also increases the risk of sliding during its insertion. ${ }^{18}$

Our results differ from other findings ${ }^{11}$ conducted in typodont teeth. To evaluate the efficiency of more angulated miniscrew insertion in contrast with the more vertical insertion, the methods of the study conducted in typodont teeth should use mannequins with different shapes and dispositions of roots and vestibular cortical (bone). When the evaluation is made in a typodont with divergent roots, it should produce different clinical results from those of simulations performed in mannequins which perhaps present convergent roots. In this study, ${ }^{11}$ only one type of typodont was used, leading to an analysis of the efficiency in only that clinical situation, which may differ from others. Other studies in mannequins must be conducted with a minimum of three clinical situations of roots disposition (convergent roots, divergent roots and parallel roots), in order to be compared with studies carried out with tomographies.

Although the present study suggests that in a region with greater interradicular space, the angulation is not a determinant factor in the positioning of the miniscrew, clinically, this change could modify the height of the line of force action and, consequently, the orthodontic mechanics.

Reduction in the angle of placement during miniscrew insertion, with the purpose of diminishing the risks of contact of the body with the root was not shown to be efficient, considering that in $40 \%$ of the virtual miniscrews inserted at an angulation of $40^{\circ}$ and $50^{\circ}$, the body was superimposed on the maxillary sinus.

Evaluation of the interradicular spaces at the three points on the miniscrew (A, B and C), performed in the four groups of types of roots (general, convergent, divergent and parallel), at four angulations $\left(70^{\circ}, 60^{\circ}, 50^{\circ}\right.$ and $\left.40^{\circ}\right)$, was rather similar. On an average this trend towards increase or reduction in interradicular space was not statistically significantly. 


\section{CONCLUSIONS}

The change in insertion angle is not a determinant factor in the positioning of miniscrews body in a region with larger interradicular space in posterior maxilla.

\section{Author contributions}

Conceived and designed the study: HMV, SASV. Data acquisition, analysis or interpretation: HMV, SASV. Writing the article: HMV, SASV. Critical revision of the article: MVF, HCV, MSJ, CCM. Final approval of the article: HMV, SASV.

\section{REFERENCES}

1. Kyung HM, Park HS, Bae SM, Sung JH, Kim IB. Development of orthodontic micro-implants for intraoral anchorage. J Clin Orthod. 2003 June;37(6):321-8: quiz 314

2. Melsen B. Mini-Implants: Where Are We? J Clin Orthod. 2005 Sept;39(9):539-47: quiz 531-2.

3. Yang L, Li F, Cao M, Chen H, Wang X, Chen X, et al. Quantitative evaluation of maxillary inter-radicular bone with cone-beam computed tomography for biotical placement of orthodontic mini-implants. Am J Orthod Dentofacial Orthop. 2015 June;147(6):725-37.

4. Hembree M, Buschang PH, Carrillo R, Spears R, Rossouw PE. Effects of intentional damage of the roots and surrounding structures with miniscrews implants. Am J Orthod Dentofacial Orthop. 2009 Mar:135(3):280.e1-9 discussion 280-1.

5. Kadioglu O, Büyükyilmaz T, Zachrisson BU, Maino BG. Contact damage to root surfaces of premolars touching miniscrews during orthodontic treatment. Am J Orthod Dentofacial Orthop. 2008 Sept;134(3):353-60.

6. Brisceno CE, Rossouw PE, Carrillo R, Spears R, Buschang PH. Healing of the roots and surrounding structures after intentional damage with miniscrews implants. Am J Orthod Dentofacial Orthop. 2009 Mar:135(3):292-301.

7. Asscherickx K, Vannet BV, Wehrbein H, Sabzevar MM. Root repair after injury from mini-screw. Clin Oral Implants Res. 2005 Oct;16(5):575-8.

8. Dobranszki A, Faber J, Scatolino IVMC, Dobranszki NPAC, Toledo AO. Analysis of factors associated with orthodontic microscrew failure. Braz Dent J. 2014:25(4):346-51.

9. Poggio PM, Incorvat C, Velo S, Carano A. "Safe Zones": A Guide for Miniscrew Positioning in the Maxillary and Mandibular Arch. Angle Orthod. 2006 Mar:76(2):191-7.

10. Park HS, Bae SM, Kyung HM, Sung JH. Micro-implant anchorage for treatment of skeletal Class I bialveolar protrusion. J Clin Orthod. 2001 July; 35(7):417-22.

11. Antoszewska J, Trześniewska P, Kawala B, Ludwig B, HS Park. Qualitative and quantitative evaluation of root injury risk potentially burdening insertion of miniscrew implants. Korean J Orthod. 2011;41(2):112-20.

12. Wilmes B, Su YY, Drescher D. Insertion Angle Impact on primary stability of orthodontic mini-implants. Angle Orthod. 2008 Nov; 78(6):1065-70.

13. Choi JH, Park CH, Yi SW, Lim HJ, Hwang HS. Bone density measurement in interdental areas with simulated placement of orthodontic miniscrew implants Am J Orthod Dentofacial Orthop. 2009 Dec;136(6):766.e1-12; discussion 766-7.
14. Park HS, Lee YJ, Jeong SH, Kwon TG. Density of the alveolar and basal bones of the maxilla and the mandible. Am J Orthod Dentofacial Orthop. 2008 Jan:133(1):30-7.

15. Baumgaertel S, Hans MG. Buccal cortical bone thickness for mini-implant placement. Am J Orthod Dentofacial Orthop. 2009 Aug;136(2):230-5.

16. Woodall N, Tadepalli SC, Qian F, Grosland NM, Marshall SD, Southard TE. Effect of miniscrew angulation on anchorage resistance. Am J Orthod Dentofacial Orthop. 2011 Feb:139(2):e147-52

17. Pickard MB, Dechow P, Rossouw PE, Buschang PH. Effects of miniscrew orientation on implant stability and resistance to failure. Am J Orthod Dentofacial Orthop. 2010 Jan;137(1):91-9.

18. Kravitz ND, Kusnoto B. Risks and complications of orthodontic miniscrews. Am J Orthod Dentofacial Orthop. 2007 Apr:131(4 Suppl):S43-51.

19. Liou EJ, Chen PH, Wang YC, Lin JC. A computed tomographic image study on the thickness of the infrazygomatic crest of the maxilla and its clinical implications for miniscrew insertion. Am J Orthod Dentofacial Orthop. 2007 Mar:131(3):352-6

20. Antoszewska J, Papadopoulos MA, Park HS, Ludwig B. Five-year experience with orthodontic miniscrew implants: a retrospective investigation of factors influencing success rates. Am J Orthod Dentofacial Orthop. 2009 Aug:136(2):158.e1-10; discussion 158-9

21. Park HS, Jeong SH, Kwon OW. Factors affecting the clinical success of screw implants used as orthodontic anchorage. Am J Orthod Dentofacial Orthop. 2006 July;130(1):18-25.

22. Gracco A, Tracey S, Baciliero U. Miniscrew insertion and the maxillary sinus: an endoscopic evaluation. J Clin Orthod. 2010 July:44(7):439-43.

23. Kuroda S, Yamada K, Deguchi T, Hashimoto T, Kyung HM, Takano-Yamamoto T. Root proximity is a major factor for screw failure in orthodontic anchorage. Am J Orthod Dentofacial Orthop. 2007 Apr;131(4 Suppl):S68-73.

24. Park HS, Hwangbo ES, Kwon TG. Proper mesiodistal angles for microimplant placement assessed with 3-dimensional computed tomography images. Am J Orthod Dentofacial Orthop. 2010 Feb;137(2):200-6

25. Houston WJ, Maher RE, McElroy D, Sherriff M. Sources of error in measurements from cephalometric radiographs. Eur J Orthod. 1986 Aug;8(3):149-51. 